\title{
Antenna with Defected Ground Structure for future mobile and Wireless communication 5G
}

\author{
Mondir anouar*, Pr.setti larbi \\ FPL, Department of physic \\ Abdelmal Essaadi university Avenue Khenifra, Tétouan 93000,Morocco. \\ Tel: +212665678652;E-mail: mondir.anouar06@gmail.com \\ Tel :+21266203667 ; E-mail:Settilarbi@gmail.com.
}

\begin{abstract}
The scope of this study is to design and develop a miniature antenna for future mobile and wireless communication 5G.On this paper is designed a new type DGS antenna for future mobile. The size of this antenna is $5.33 \mathrm{~mm}$ width and $6.67 \mathrm{~mm}$ long, with dielectric constant $\varepsilon_{-} r=2.2$ and thickness $\mathrm{H}=0.8 \mathrm{~mm}$. The new patch antenna has $\mathrm{T} \& \mathrm{U}$ slotted and notches. $50 \mathrm{ohm}$ single microstrip line feeding with radiation patch, which is resonant with the dual band frequencies. The design and simulation results are analyzed the return loss, VSWR, surface current distribution, Fairfield radiation pattern and Fairfield gain. This antenna obtained the return loss $-20.16576 \mathrm{~dB}$ and $-28.7672 \mathrm{~dB}$ which cover the $27.58443 \mathrm{GHz}$ to $27.652 \mathrm{GHz}$ and $29.284 \mathrm{GHz}$ to $29.318 \mathrm{GHz}$ band. The Fairfield gain have a $7.35 \mathrm{~dB}$ and $5.11 \mathrm{~dB}$. This antenna operates dual band frequency $27.626 \mathrm{Gz}$ and $29.303 \mathrm{GHz}$ for $5 \mathrm{G}$ communication is presented..
\end{abstract}

Keywords: DGS antenna theory, filter DGS.T\&U Slotted,notches,5G communication,mmwave

\section{Introduction}

Utilization of the millimeter wave (mmWave) band is a key technology for the development of the heterogeneous networks (HetNets) that will be used for $5^{\text {th }}$ generation wireless cellular networks $(5 \mathrm{G})[1]$.

The beams generated in mmwave (band ka) are much more directive than in lower frequency bands. This why it's reserve for the communications satellite. Its frequency band between $26.5 \mathrm{GHz}$ and $40 \mathrm{GHz}$, The big problem when used mmwave absorption and attenuation with environment, For example, the oxygen molecule (O2) normally absorb electromagnetic energy at $60 \mathrm{Ghz}$ to a much higher degree than in the regions $30-160 \mathrm{Ghz}$. The rain attenuation and atmospheric absorption characteristics of mmwave propagation. The solution proposed for this type of frequency band it is of added by small base station with Distance less than $1 \mathrm{Km}$. Moreover used (MIMO)multiple antennas at the transmitter and /or receive improve the global performance of wireless systems .

For working the huge of frequency band size of antenna change smaller and become a many defiance for fabrication. This paper, design a new antenna by depends on merging three ideas in [1] [2] [3] which works the dual band of $f 1=27.632 \mathrm{GHz}$, $\mathrm{f} 2=29.3032 \mathrm{GHz}$ frequency use for future $5 \mathrm{G}$ wireless and mobile communication is presented. In [3] is created a novel topology of antenna patch with mesh-grille, and also is proposed a position for the antenna to be installed that avoids the problem of attenuation of the wave with the user. In [4] is developed a new concept of antenna patch with a slot with shape ' $T$ ' and ' $\mathrm{L}$ ' to be used in band frequency 28Ghs. In [5] is proposed a circular patch with DGS that improves the performance of other antennas. 
In [6] is proposed an antenna with a ' $U$ ' slot bi-band in $28 \mathrm{Ghz}$ and $38 \mathrm{Ghz}$, and added an array of an antenna to improve their performance.

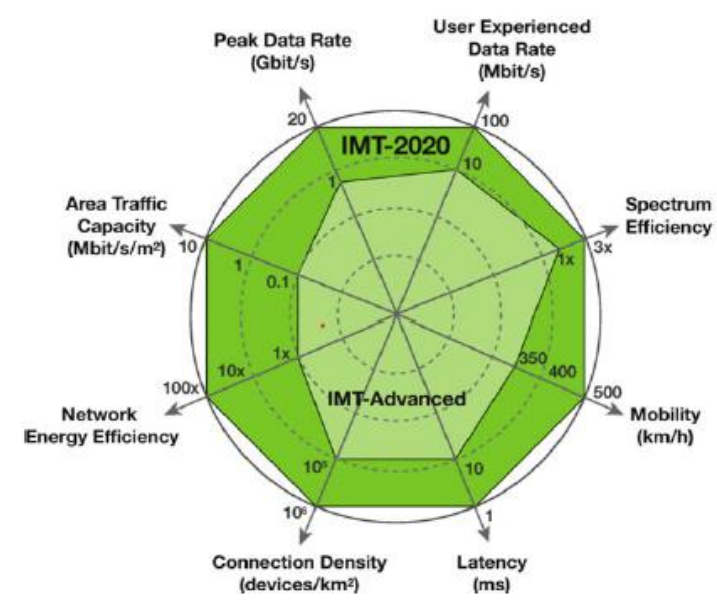

Fig. 1. Enhancement of key capabilities from IMT-Advanced to IMT-2020[13]

\section{Geomrtry of new type}

The geometry of the new antenna is presented in fig (1). The size of this antenna is $5 \mathrm{~mm}$ width and $6.33 \mathrm{~mm}$ long, with dielectric constant $\varepsilon_{-} r=2.2$ with thickness $\mathrm{H}=0.8 \mathrm{~mm}$. The new patch antenna has T\&U slotted and notches. $50 \mathrm{ohm}$ single microstrip line feeding with radiation patch, which is resonant with the dual band frequencies.

Before calculating the length of the patch it is necessary to calculate the effective dielectric constant, effective with and length extension of the resulting length by using the equation:

$$
\begin{gathered}
\varepsilon_{e f f}=\frac{\varepsilon_{r}+1}{2}+\frac{\varepsilon_{r}-1}{2}\left[1+12 \frac{h}{W}\right]^{-\frac{1}{2}} \\
L_{e f f}=L+2 \Delta L \\
L_{e f f}=\frac{c}{2 f_{0} \sqrt{\varepsilon_{e f f}}}
\end{gathered}
$$

All the dimensions presented in table.1, table.2, table.3. 


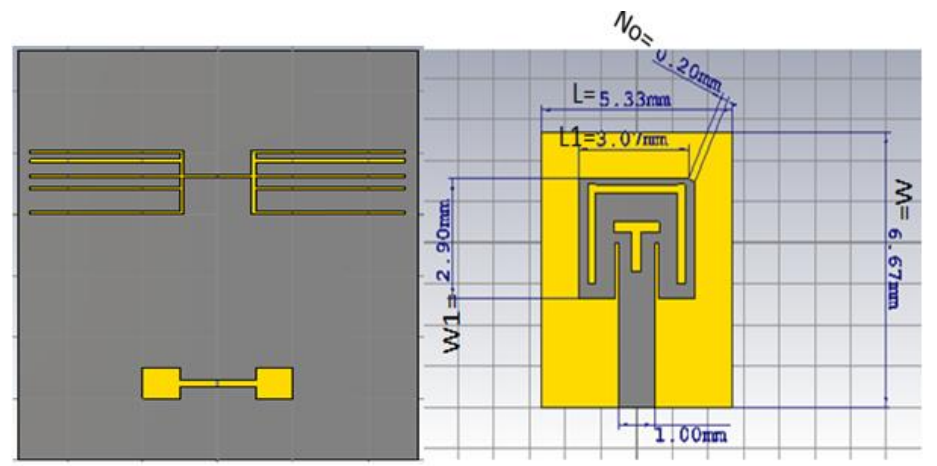

Fig. 2. Geometry of proposed antenna with DSG unit cell and DGS filter

Table 1: dimensions of patch antenna

\begin{tabular}{|l|l|}
\hline Parameters & Dimensions (mm) \\
\hline L & 5.33 \\
\hline W & 6.67 \\
\hline L1 & 3.07 \\
\hline W1 & 2.9 \\
\hline NO & 0.2 \\
\hline
\end{tabular}

Fig. 3 and table. 2 present the geometry and dimensions of the filter DGS .

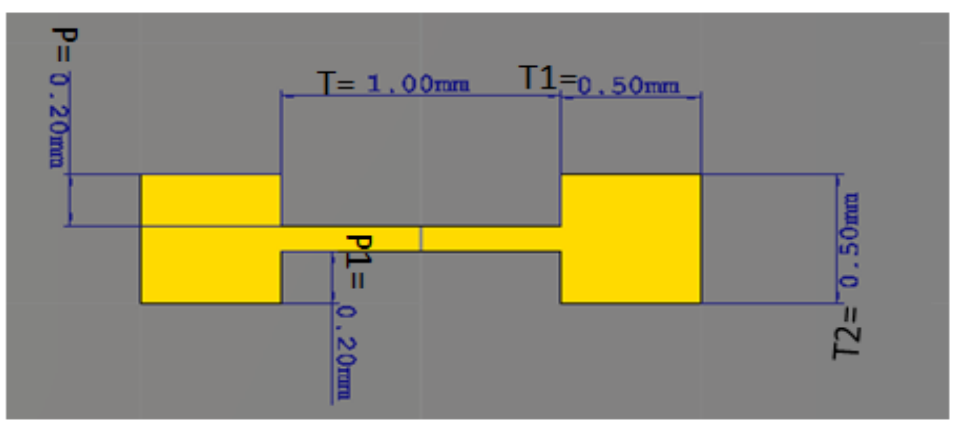

Fig.3. Geometry of proposed DGS filter

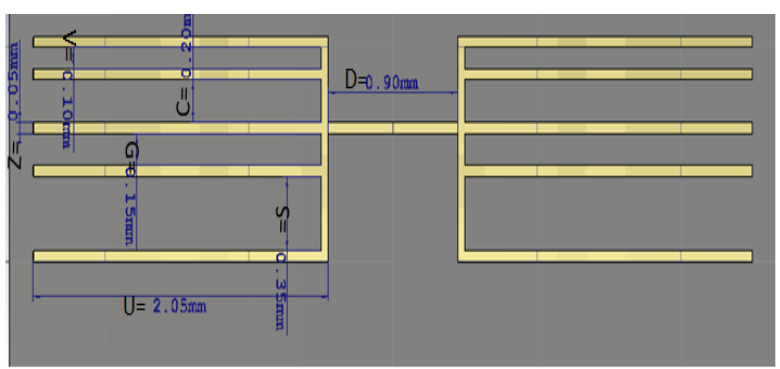

Fig.4. Geometry of proposed DGS unit cell 
Table 2: dimensions of DGS filter.

\begin{tabular}{|l|l|}
\hline Parameters & Dimensions $(\mathbf{m m})$ \\
\hline $\mathrm{P}$ & 0.2 \\
\hline $\mathrm{T}$ & 1 \\
\hline $\mathrm{T} 1$ & 0.5 \\
\hline $\mathrm{T} 2$ & 0.5 \\
\hline $\mathrm{P} 1$ & 0.2 \\
\hline
\end{tabular}

And the sconde table.3. present the geometry of unit cell

Table 3: dimensions of DGS filter

\begin{tabular}{|l|l|}
\hline Parameters & Dimensions $(\mathbf{m m})$ \\
\hline D & 0.9 \\
\hline C & 0.3 \\
\hline G & 0.15 \\
\hline V & 0.1 \\
\hline Z & 0.05 \\
\hline U & 2.05 \\
\hline S & 0.35 \\
\hline
\end{tabular}

\section{DGS antenna theory}

In general, circuit equivalent of this structure DGS to consist of a circuit LC parallel and series with the transmission line:

Fig.5 represent DGS equivalent

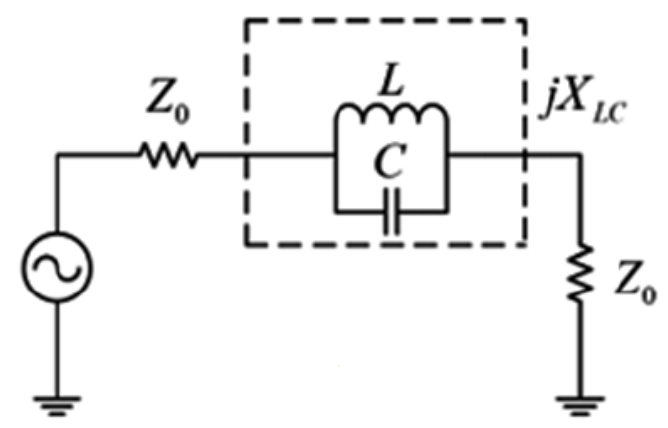

Fig.5. Equivalent circuit LC 
The next calcul we take into consideration the lossless we insert resistance in parallel like illustrated in fig (2)

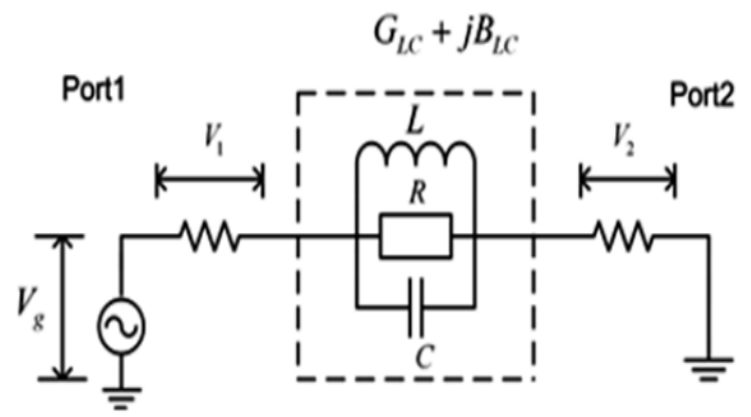

Fig.6. Equivalent circuit LRC

So the equivalent circuit is given by:

$$
Y=\frac{1}{R}+j 2 \pi\left(C f-\frac{1}{4 \pi^{2} L f}\right)
$$

Because:

$$
\begin{gathered}
Z=\frac{1}{Y} \\
Z=\frac{1}{\frac{1}{R}+j 2 \pi\left(C f-\frac{1}{4 \pi^{2} L f}\right)}
\end{gathered}
$$

And we know:

$$
S_{21}=\frac{1}{1+\frac{1}{2} Z Z_{0}^{-1}}
$$

At $-3 \mathrm{db}$ we find:

$$
\left|S_{21}\right|=\frac{2 Z_{0}}{\sqrt{4 Z_{0}^{2}+\left(\frac{w_{c}}{w_{0}^{2}-w_{c}^{2}}\right)^{2}}}=\frac{1}{\sqrt{2}}
$$

- $\quad w c$ is the angular cutoff frequency. 
- $\mathrm{w} 0$ is the angular resonance frequency

At the resonance frequency we calculate the resistance $\mathrm{R}$ replacing $\mathrm{Ze}=\mathrm{R}$ and we find:

$$
\left.S_{21}\right|_{w=w_{0}}=\left|\frac{2 Z_{0}}{2 Z_{0}+Z_{e}}\right|=\frac{2 Z_{0}}{2 Z_{0}+R}
$$

This gives:

$$
R=\frac{2 Z_{0}\left(1-\left.S_{21}\right|_{w=w_{0}}\right)}{\left.S_{21}\right|_{w=w_{0}}}
$$

The current distribution through the patch, by increasing the length electric current Which leads to increased capacitance and the inductor and consequently the antenna has characteristics slow wave.

The slow wave factor (SWF) shows the relationship between the number in free space, $\mathrm{k} 0$ and the propagation constant of the line of transmission.SWF is determined by:

$$
S W F=\sqrt{\varepsilon_{e}}
$$

With :

$$
\varepsilon_{e}=\frac{\varepsilon_{r}+1}{2}+\frac{\varepsilon_{r}-1}{2}\left[1+12 \frac{h}{w}\right]^{-\frac{1}{2}}
$$

In addition, the propagation constant is given by:

$$
\beta=\sqrt{\varepsilon_{e}} \cdot k_{0}
$$

Which gives therefore:

$$
S W F=\frac{\beta}{k_{0}}
$$




\section{Simulated results}

The DGS filtre and unit cell MMW frequency antenna for 5G networks is presented in Fig.5.

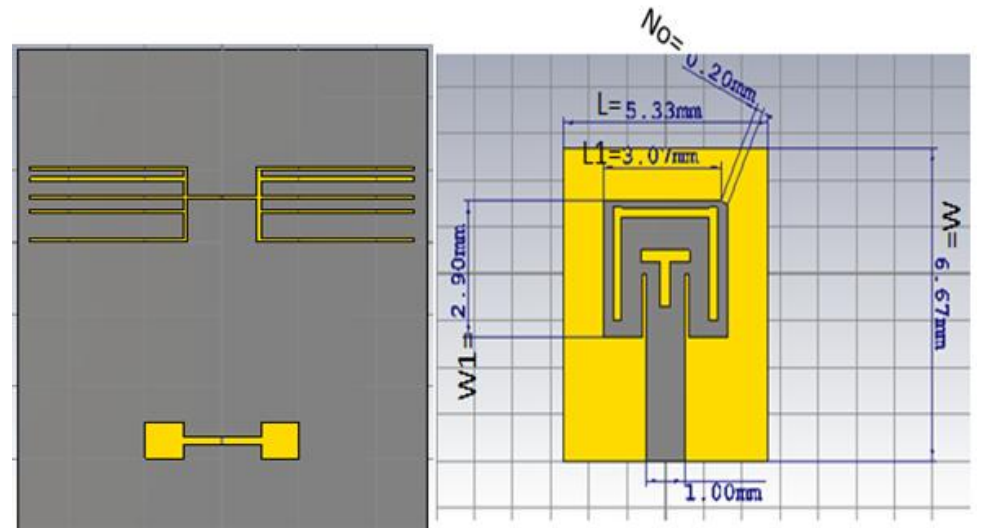

Fig.5. Geometry of proposed antenna

At first we begin with the introduction of a unit cell fig 6 and in one Second time we introduce the filter DGS fig. 11.

4.1 Patch antenna with unit cell :

Fig.6 illustrates the patch scheme with the DGS cell unit engraved in the ground plane.
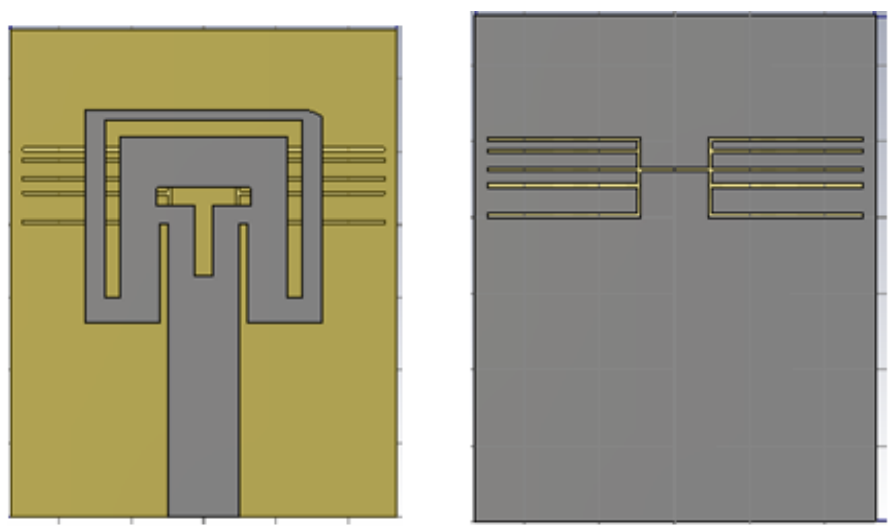

Fig.6. the DGS cell unit engraved in the ground plane.

The engraving of the slots and notches on the patch we note an improvement at the level of adaptation by keeping the resonant frequency Intact. 
On the pretext that we want to further improve the adaptation of the antenna, we add breaks on the patch as shown in the fig6.

Fig.7. is present the simulated Sparameter of designed antenna with DGS unit cell and Fig. 8 is present the simulated VSWR. Its result obtained at $\mathrm{f} 1 \mathrm{for}$ good matching impedance of dual band antenna. Notice that the resonance frequency of the antenna, with coefficient of reflection which is equal to $S 11_{f 1}=-25.119848 \mathrm{~dB} S 11_{f 2}=$ $16.4987 \mathrm{~dB}$ and $V S W R_{f 1}=1.35$ and $V S W R_{f 2}=1.2345$. the gain of the proposed antenna is equal $G_{f 1}=7.16 \mathrm{~dB}, G_{f 1}=4.18 \mathrm{~dB}$ Fig.9.

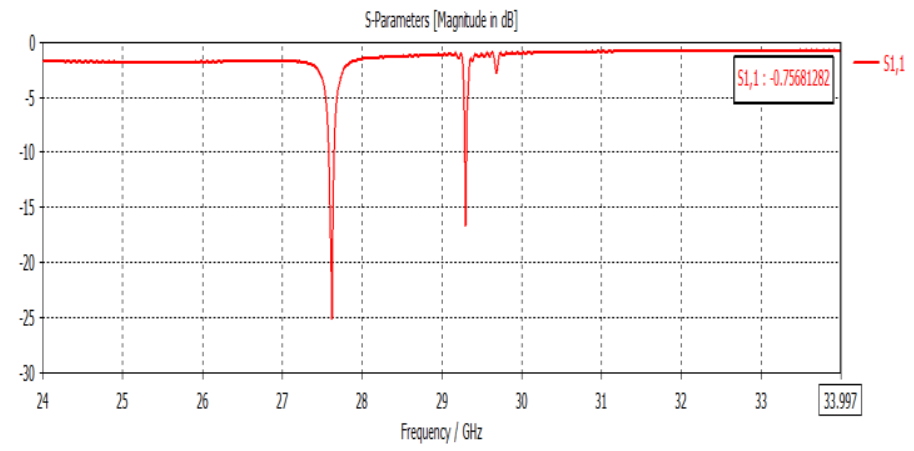

Fig.7: Simulated S-parameter of designed DGS unit cell

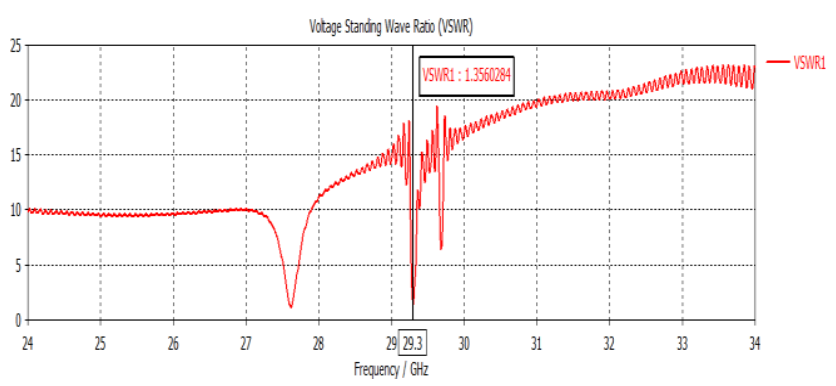

Fig.8: Simulated VSWR result of designed DGS unit cell 


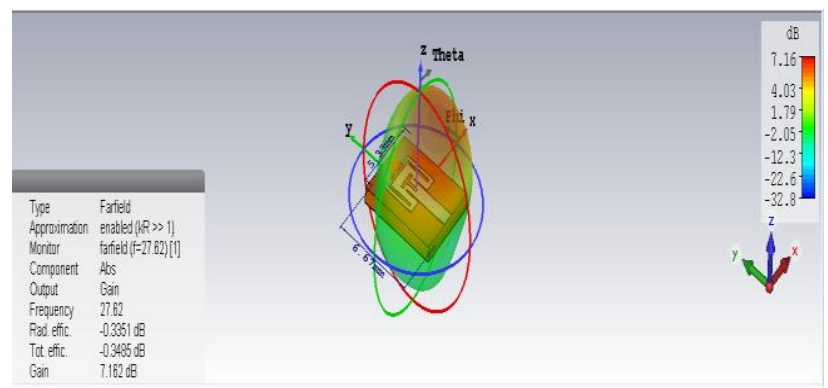

Fig. 11: Simulated 3D radiation pattern of DGS unit cell f1.

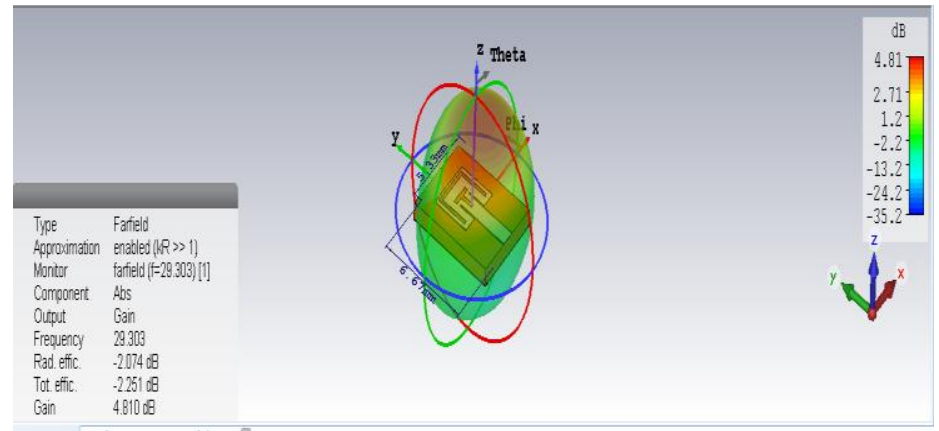

Fig. 12: Simulated 3D radiation pattern of DGS unit cell f2.

4.2 Patch antenna with DGS filter and unit cell :
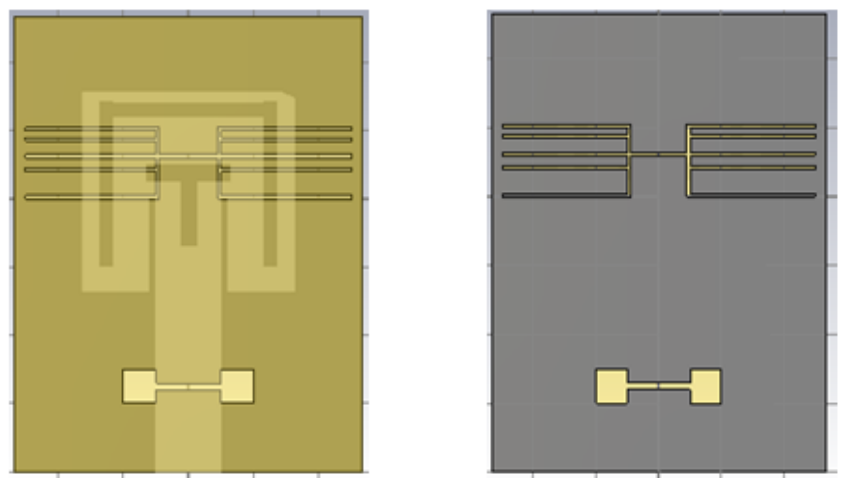

Fig.13: Geometry of proposed designed Unit cell and DGS filter

To understand the effect of introducing the DGS structure to the antenna patch we did a study same structure .but this time we engraved it on the ground plane of a transmission line the geometry of the filter is shown in fig. 13. 
Fig.(14,15,16,17) are present the simulated $S$ parameter of designed microstrip patch antenna and VSWR and gain . This simulated result obtained the $\mathrm{F} 1=27.636 \mathrm{GHz}$ and $\mathrm{F} 2=29.323 \mathrm{GHz}$ of resonant frequency have a return loss $S 11_{f 1}=-20.119848 \mathrm{~dB}$ $S 11_{f 2}=-28.7672 \mathrm{~dB}$ and $V S W R_{f 1}=1.2862 \mathrm{and} V S W R_{f 2}=1.07$.the gain of the proposed Antenna is equal $G f 1=7.35 \mathrm{~dB}, G f 2=5.11 \mathrm{~dB}$.

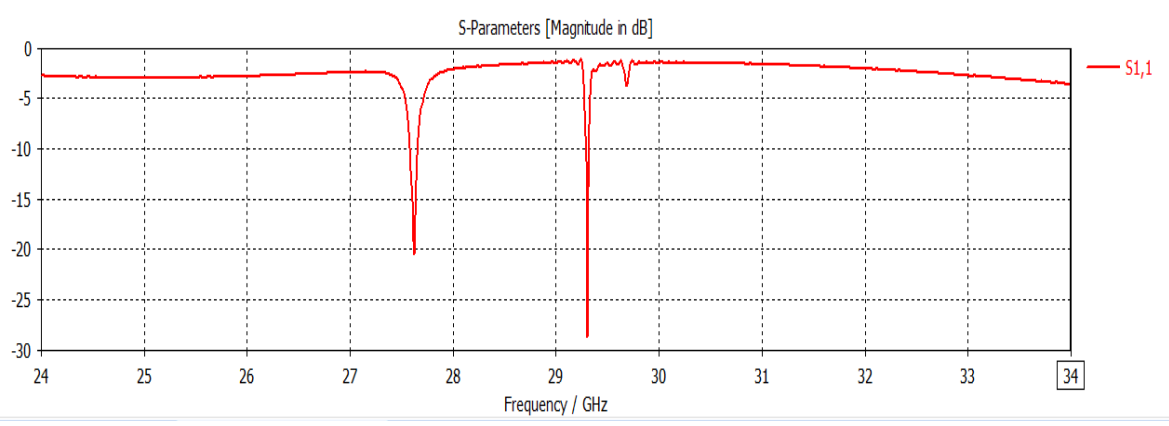

Fig. 14: Simulated S-parameter of designed DGS unit cell and DGS filter

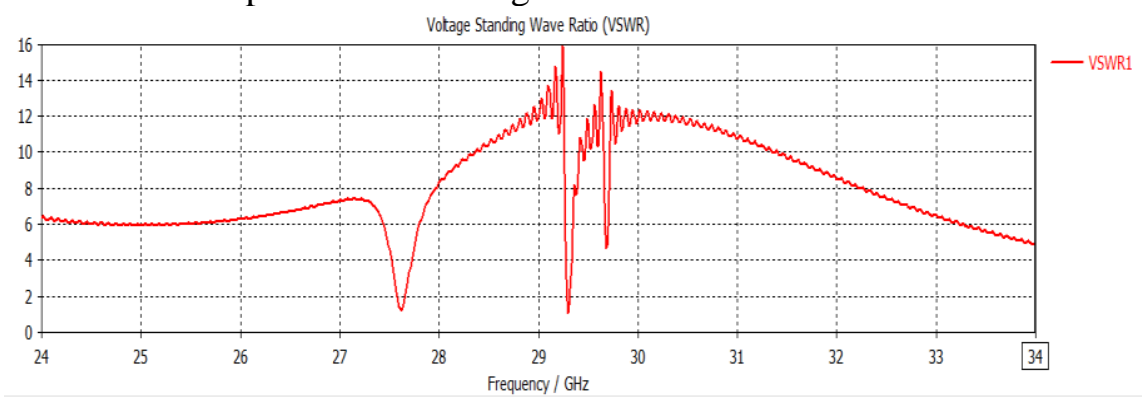

Fig.15: Simulated VSWR result of designed DGS unit cell and DGS filter

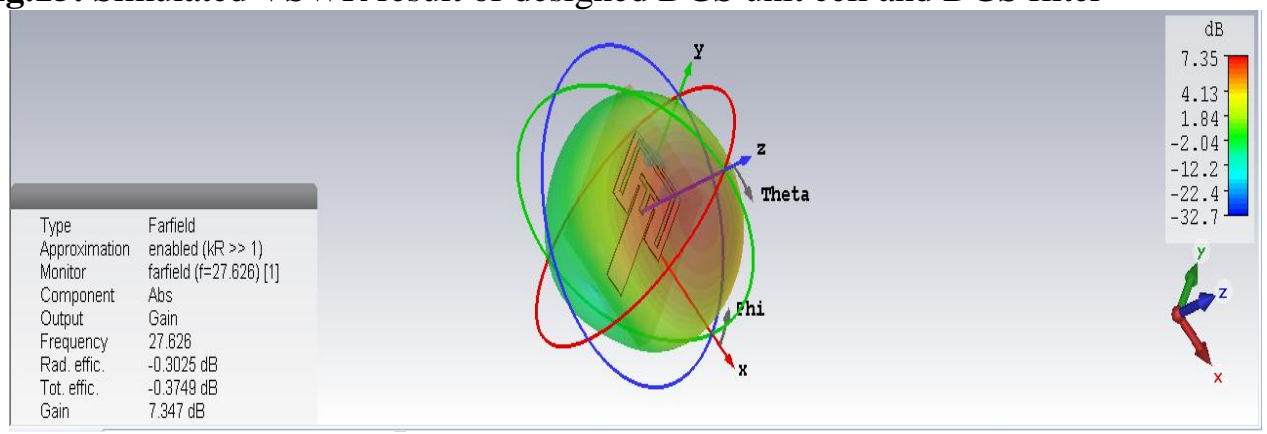

Fig. 11: Simulated 3D radiation pattern of DGS unit cell and DGS filter f1. 


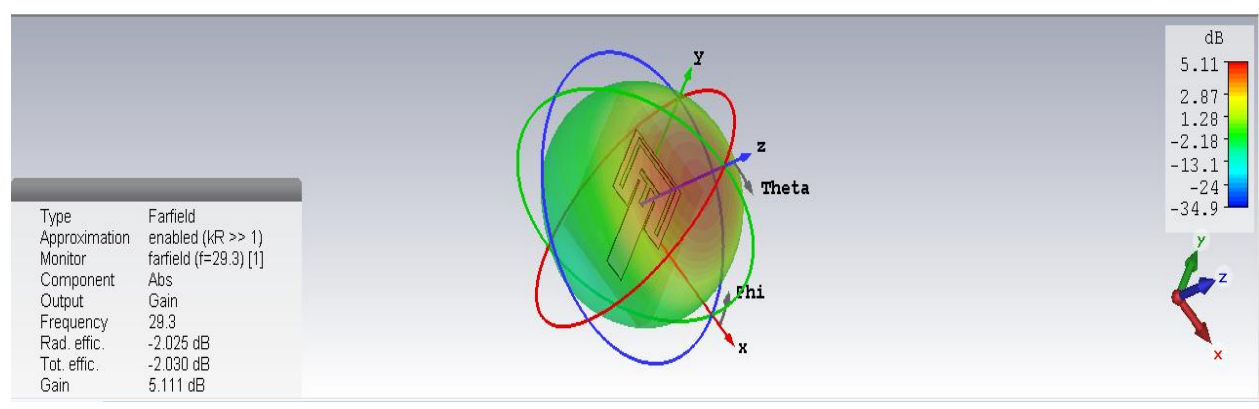

Fig. 11: Simulated 3D radiation pattern of DGS unit cell and DGS filter f2

Note that the gain of the antenna with DGS cells for the frequency $\mathrm{f} 1=27.626$ equal to $7.16 \mathrm{~dB}$ and for a frequency $\mathrm{f} 2=29.303 \mathrm{GHZ}$, Gain equal to $4.17 \mathrm{~dB}$.when adding DGS filter the gain increases from $7.16 \mathrm{~dB}$ for $\mathrm{f} 1$ and $5.11 \mathrm{~dB}$ for f2 in table (4) we have a comparison between antenna with unit cell and we adding the filter DGS .

Table 4: Comparison of designed antenna DGS unit cell with antenna DGS unit cell \& DGS filter

\begin{tabular}{|l|l|l|l|l|}
\hline & \multicolumn{1}{|c|}{$\mathrm{F}(\mathrm{Ghz})$} & \multicolumn{1}{|c|}{$\mathrm{G}(\mathrm{dB})$} & \multicolumn{1}{|c|}{$\mathrm{VSWR}$} & \multicolumn{1}{|c|}{$\mathrm{S} 11(\mathrm{~dB})$} \\
\hline $\begin{array}{l}\text { Unit } \\
\text { cell }\end{array}$ & $\mathrm{F} 1=27.63$ & $G_{f 1}=7.16$ & $V S W R_{f 1}=1.35$ & $S 1_{f 1}=-25.11984$ \\
DGS & $\mathrm{F} 2=29.323$ & $G_{f 2}=4.18$ & $V S W R_{f 2}=1.2345$ & $S 11_{f 2}=-16.4987$ \\
\hline $\begin{array}{l}\text { Add } \\
\text { filter }\end{array}$ & $\mathrm{F} 1=27.63$ & $G_{f 1}=7.35$ & $V S W R_{f 1}=1.2862$ & $S 11_{f 1}=-20.119848$ \\
DGS & $\mathrm{F} 2=29.323$ & $G_{f 2}=5.11$ & $V S W R_{f 2}=1.07$ & $S 11_{f 2}=-28.7672$ \\
\hline
\end{tabular}

Table 5: Comparison of designed antenna with other reference antenna

\begin{tabular}{|l|l|l|l|l|}
\hline & \multicolumn{1}{|c|}{ [2] } & \multicolumn{1}{c|}{ [1] } & \multicolumn{1}{c|}{ [3] } & \multicolumn{1}{c|}{$\begin{array}{c}\text { Antenna } \\
\text { proposed }\end{array}$} \\
\hline Gain db & 7.77 & $5.54,6.4$ & $15.6-10$ & $5.35-7.11$ \\
\hline $\mathrm{S} 11(\mathrm{~dB})$ & -31.24 & $-35.73,-47.53$ & $-50,-40$ & -20.119848, \\
& & & & -28.7672 \\
\hline $\begin{array}{l}\text { Resonant } \\
\text { Frequency(Ghz) }\end{array}$ & 30 & 28,28 & & $28-39.95$ \\
\hline size & & & & 29.323 \\
mm $\times$ mm & $10 \times 10$ & $10 \times 10$ & $16 \times 16$ & $5.33 \times 6.67$ \\
\hline
\end{tabular}

\section{CONCLUSION}

In this paper,the DGS structure has been presented and we analysed different parameters by CST simulator.The detail of the design approach presented in the article may beprone to modification amid evolution of wireless devices in the future. 
Nonethelss ,the authors predic the methodologies able to help to increases gaon of this antenna, we can also add array antenna for the same reason.

The antenna obtained is characterized by a better adaptation, more bandwidth and greater gain and directivity which make it suitable to respond to the majority of constraints imposed by the modern telecommunication systems.

\section{ACKNOWLEDGMENT}

The authors would like to thank my professor Larbi SETTI for valuable discussions and feedback.

\section{REFERENCES}

[1] saini and S. K. agarwal, "T and L slotted patch Antenna for future mobile and wireless communication". in 2017 8th International Conference on Computing”, Communication and Networking Technologies .in 2017

[2] A. zaidi and A. . baghdad,A. badri "Design and optimization of an inset fed circular microstrip patch antenna using DGS structure for applications in millimeter wave band". International Conference onWireless Networks and Mobile Communications (WINCOM) .in 2016

[3] U. Rafique and H. . khalil,H. saif-Ur-Rehma "Dual-band microstrip patch antenna array for 5G mobile"communications.in 2017 Progress in Electromagnetics Research Symposium - Fall(PIERS FALL) (2017).in

[4] F. Rainville and. P. Harackiewicz "Magnetic tuning of a microstrip patch antenna fabricated on a ferrite film”. Articles 5(1992)..in 2017.

[6] A. makoto miao . j. hirokawa . k. sakaguchi. tanighuchi. Makoto" Demonstration of mmWave Systems and Networks for the HetNet in 5G Mobile"Communication.in 2016

[7] Tadilo. Endeshaw Bogale Long .Bao” Massive MIMO and mmWave for 5G Wireless HetNet".in 2016

[8] M.khandelwal,B.kanaujia,S.kumar“ Defected ground structure: fundamentals, analysis, and applications in modern wireless" s-International Journal of Antennas and Propagation , 2017 hindawi.com

[8] Theodore S.Rappaport,shu sun,Rimma mayzus,Hang zhao,yaniv azar,Kevin wang,georef N,wong Jocelyn k shulz, Mathew Samimi and felix gutirrez "Millimeter Wave Mobile Communications for 5G

Cellular: It Will Work!” IEEE Digital Object Identifier 10.1109/ACCESS.2013.2260813. 